\title{
The Middle East Respiratory Syndrome Coronavirus - A Continuing Risk to Global Health Security
}

\author{
Esam I. Azhar, Simone Lanini, Giuseppe Ippolito, \\ and Alimuddin Zumla
}

\begin{abstract}
Two new zoonotic coronaviruses causing disease in humans (Zumla et al. 2015a; Hui and Zumla 2015; Peiris et al. 2003; Yu et al. 2014) have been the focus of international attention for the past 14 years due to their epidemic potential; (1) The Severe Acute Respiratory Syndrome coronavirus (SARS-CoV) (Peiris et al. 2003) first discovered in China in 2001 caused a major global epidemic of the Severe Acute Respiratory Syndrome (SARS). (2) The Middle East respiratory syndrome coronavirus (MERS-CoV) is a new corona virus isolated for the first time in a patients who died of severe lower respiratory tract infection in Jeddah (Saudi Arabia) in June 2012 (Zaki et al. 2012). The disease has been named Middle East Respiratory Syndrome (MERS) and it has remained on the radar of global public health authorities because of recurrent nosocomial and community outbreaks, and its association with severe disease and high mortality rates (Assiri et al. 2013a; Al-Abdallat et al. 2014; Memish et al. 2013a; Oboho et al. 2015; The WHO MERSCoV Research Group 2013; Cotten et al. 2013a; Assiri et al. 2013b; Memish et al. 2013b; Azhar et al. 2014; Kim et al. 2015; Wang et al. 2015; Hui et al. 2015a). Cases of MERS have been reported from all continents and have been linked with travel to the Middle East (Hui
\end{abstract}

E.I. Azhar $(\bowtie)$

Special Infectious Agents Unit, King Fahd Medical Research Centre, Jeddah, Saudi Arabia

Medical Laboratory Technology Department, Faculty of Applied Medical Sciences, King Abdulaziz University, Jeddah, Saudi Arabia

e-mail: eazhar@kau.edu.sa

S. Lanini

Epidemiology and Preclinical Research Department, INMI Lazzaro Spallanzani, Via Portuense 292, 00149 Rome, Italy

e-mail: simone.lanini@inmi.it
G. Ippolito

National Institute for Infectious Diseases Lazzaro Spallanzani, Via Portuense, 292, 00149 Rome, Italy e-mail: giuseppe.ippolito@inmi.it
A. Zumla
Division of Infection and Immunity, University College London, London, UK

NIHR Biomedical Research Centre, UCL Hospitals NHS Foundation Trust, London, UK e-mail: a.zumla@ucl.ac.uk 
et al. 2015a; WHO 2015c). The World Health Organization (WHO) have held nine meetings of the Emergency Committee (EC) convened by the Director-General under the International Health Regulations (IHR 2005) regarding MERS-CoV (WHO 2015c). There is wishful anticipation in the political and scientific communities that MERS-CoV like SARS-CoV will disappear with time. However it's been nearly 4 years since the first discovery of MERS-CoV, and MERS cases continue to be reported throughout the year from the Middle East (WHO 2015c). There is a large MERS-CoV camel reservoir, and there is no specific treatment or vaccine (Zumla et al. 2015a). With 10 million people visiting Saudi Arabia every year for Umrah and/or Hajj, the potential risk of global spread is ever present (Memish et al. 2014a; McCloskey et al. 2014; Al-Tawfiq et al. 2014a).

\section{Keywords}

Coronavirus • MERS • MERS-CoV • Middle East • Drugs • Infection control $\bullet$ Treatment $\bullet$ Risk $\bullet$ Camels

\section{Introduction}

Two new zoonotic coronaviruses causing disease in humans (Zumla et al. 2015a; Hui and Zumla 2015; Peiris et al. 2003; Yu et al. 2014) have been the focus of international attention for the past 14 years due to their epidemic potential; (1) the Severe Acute Respiratory Syndrome coronavirus (SARS-CoV) (Peiris et al. 2003) first discovered in China in 2001 which caused a major global epidemic of the Severe Acute Respiratory Syndrome (SARS); and (2) the Middle East respiratory syndrome coronavirus (MERS-CoV) first isolated from a patient who died of severe lower respiratory tract infection in Jeddah (Saudi Arabia) in June 2012 (Zaki et al. 2012). The disease has been named Middle East Respiratory Syndrome (MERS) and it has remained on the radar of global public health authorities because of recurrent nosocomial and community outbreaks, and its association with severe disease and high mortality rates (Assiri et al. 2013a; Al-Abdallat et al. 2014; Memish et al. 2013a; Oboho et al. 2015; The WHO MERS-CoV Research Group 2013; Cotten et al. 2013a; Assiri et al. 2013b; Memish et al. 2013b; Azhar et al. 2014; Kim et al. 2015;
Wang et al. 2015; Hui et al. 2015a). Cases of MERS have been reported from all continents and have been linked with travel to the Middle East (Hui et al. 2015a; WHO 2015c). The World Health Organization (WHO) have held nine meetings of the Emergency Committee (EC) convened by the Director-General under the International Health Regulations (IHR 2005) regarding MERS-CoV (WHO 2015c). There is wishful anticipation in the political and scientific communities that MERS-CoV like SARS-CoV will disappear with time. However it's been nearly 4 years since the first discovery of MERS-CoV, and MERS cases continue to be reported throughout the year from the Middle East (WHO 2015c). There is a large MERS$\mathrm{CoV}$ camel reservoir, and there is no specific treatment or vaccine (Zumla et al. 2015a). With 10 million people visiting Saudi Arabia every year for Umrah and/or Hajj, the potential risk of global spread is ever present (Memish et al. 2014a; McCloskey et al. 2014; Al-Tawfiq et al. 2014a).

This chapter gives a succinct overview of MERS-CoV epidemiology, clinical features, and highlights the knowledge gaps and its epidemic risk potential. 


\section{Epidemiological Features of MERS-CoV}

\subsection{Discovery and Evolution}

At first identification and publication of the isolation of a novel $\beta \mathrm{CoV}$ coronavirus in September 2012 (Zaki et al. 2012), the name EMC/2012 was given to it after the laboratory at the Erasmus Medical Centre (EMC) in the Netherlands. The EMC laboratory had sequenced the virus from clinical samples shipped from a hospital in Jeddah, Saudi Arabia where a patient had died of respiratory failure in June 2012. The virus was renamed MERS-CoV after international consensus and the clinical disease it caused was called Middle East Respiratory Syndrome (MERS) (de Groot et al. 2013). In order to ascertain whether it was a new disease of humans, several retrospective and historical studies were performed on stored biobanks of patient samples in the Middle East. In particular one study showed that in April 2012 there was a hospital MERS cluster of infections in Jordan (Hijawi et al. 2013), predating the Jeddah case. Recent evolutionary studies based on whole-genome sequences and temporal analysis of infection clusters suggested that MERS-CoV most probably emerged between November 2009 and April 2012 (Cotten et al. 2013b, 2014; Penttinen et al. 2013). Ever since its first discovery, intermittent endemic cases of MERS cases are being reported throughout the year from Saudi Arabia as single cases, clusters in the community or hospital outbreaks (WHO 2015c). Furthermore there have been MERS cases reported from all continents and these have been linked to travel to the Middle East (Zumla et al. 2015a; WHO 2015c).

\subsection{Geographical Distribution}

As of 25th November, 2016, WHO reports that globally there have been 1,832 laboratoryconfirmed cases of MERS-CoV with 651 deaths reported (case fatality rate $35 \%$ ) (WHO 2015c). Twenty seven countries have reported cases of MERS to the WHO (Fig. 1): Baharain, Iran,
Jordan, Kuwait, Lebanon, Oman, Qatar, Saudi Arabia, the United Arab Emirates, and Yemen (Middle East); Austria, France, Germany, Greece, Italy, Netherlands, Turkey, and the United Kingdom (UK) (Europe); Algeria, Tunisia and Egypt (Africa); China, Malaysia, Republic of Korea, the Philippines and Thailand (Asia); and the United States of America (Americas) (WHO 2016). A large proportion of MERS cases have been reported from Saudi Arabia. The largest MERS outbreak outside Saudi Arabia occurred in hospitals in the Republic Korea in mid-2015 where MERS$\mathrm{CoV}$ was imported by a traveler to the Middle East. Poor infection control measures led to spread of MERS-CoV resulting in 184 MERS cases with 33 deaths (WHO 2015c).

\subsection{Origin and Transmission of MERS-CoV}

Several studies have sought to ascertain the natural reservoir of MERS-CoV. Studies on bat feces from Middle East, Africa and several European countries have reported $\mathrm{CoV}$ in Nycteris and Pipistrellus bats (Annan et al. 2013; Memish et al. 2013c). From Saudi Arabia, over a thousand bat samples were tested and only one fragment of MERS-CoV was found in one Taphozous bat which was related to MERS-CoV isolated from humans (Memish et al. 2013c). Several studies have subsequently indicated that MERS-CoV is a zoonotic virus and human infections have been associated with direct or indirect contact with infected dromedary camels (Reusken et al. 2013, 2014; Haagmans et al. 2014; Hemida et al. 2014; Meyer et al. 2014; Muller et al. 2014; Gossner et al. 2016). Strains of MERS-CoV have been identified in camels in several countries, including Saudi Arabia, Egypt, Oman, and Qatar. MERS-CoV antibodies have been found in camels in Africa and throughout the Middle East. Recently at least five lineages of MERS$\mathrm{CoV}$ in Saudi Arabian camels have been found (Sabir et al. 2016; Du and Han 2016). Human to human transmission of MERS-CoV has been 


\section{CONFIRMED GLOBAL CASES OF MERS-COV 2012 - 2016}

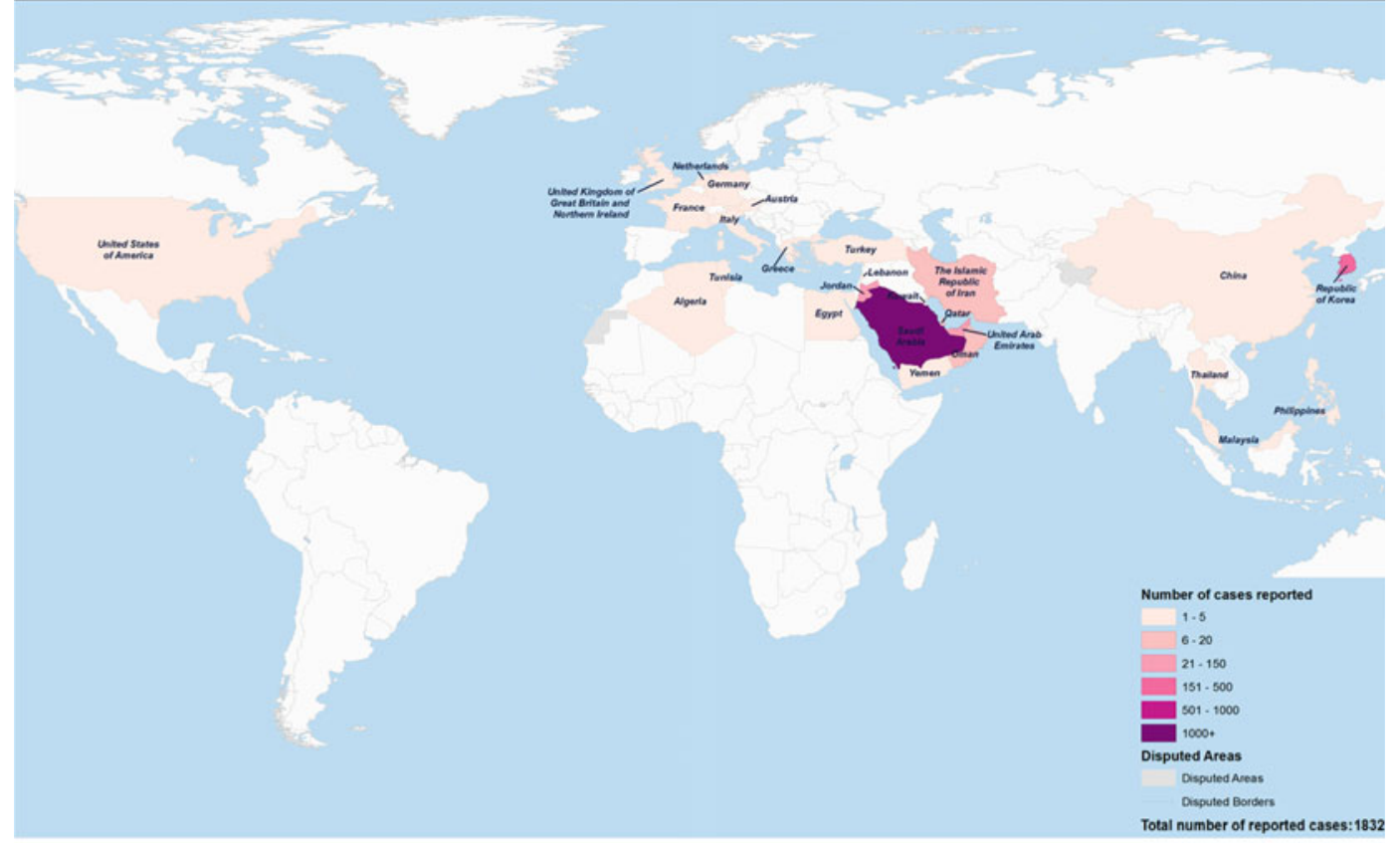

\section{Confirmed global cases of MERS-CoV}

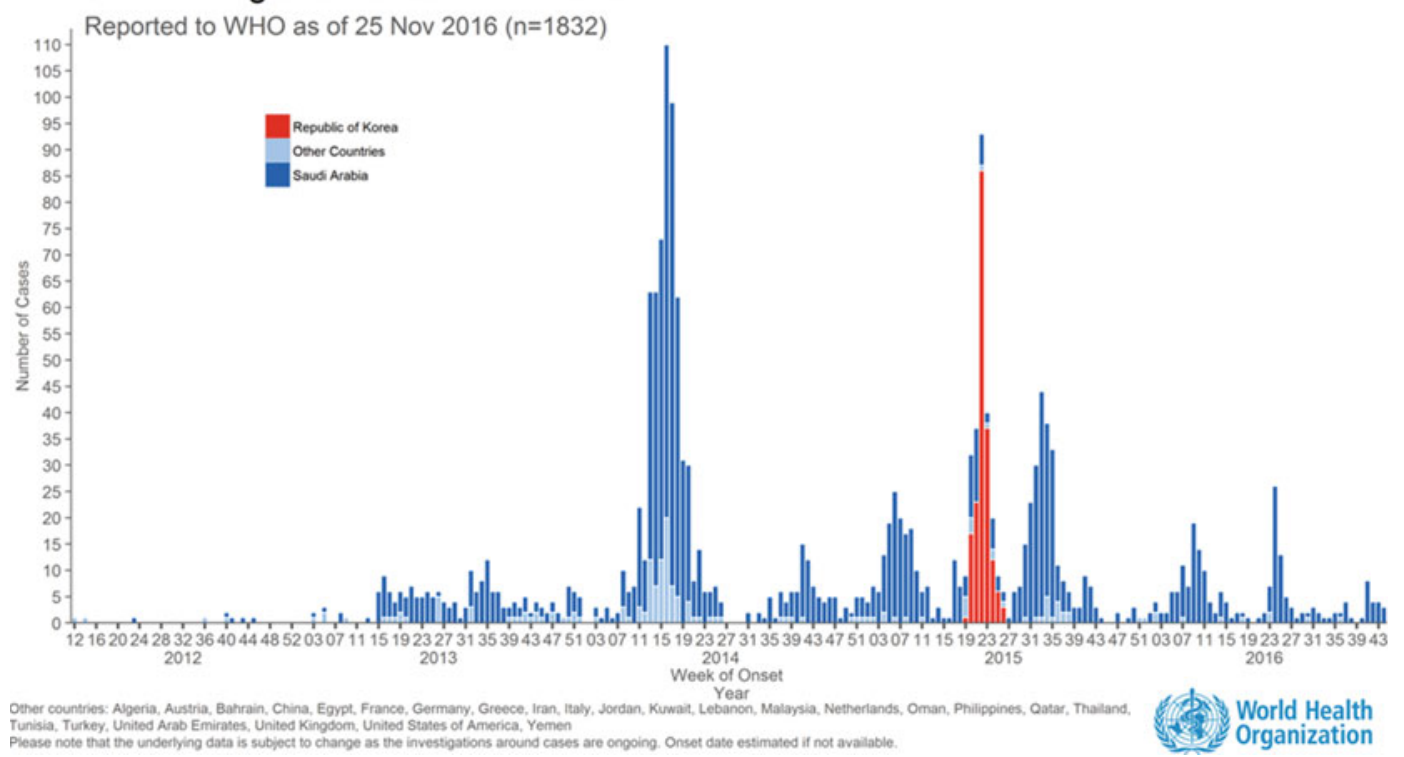

Fig. 1 Global cases of MERS-CoV infection reported to WHO (2012-2015)

documented only for close contacts of infected subjects including transmission among family members and between patients and healthcare worker (Assiri et al. 2013a, b; Cotten et al. 2013a; Memish et al. 2013b; Kim et al. 2016a; Younan et al. 2016). Convincing evidence support the hypothesis that dromedary camel are a natural reservoir of the infection and that this animal species can have a primary role for the transmission of MERS-CoV to human beings. However, only a small proportion of the primary cases have reported contact with 
camels. The apparent rarity of MERS-CoV transmission from primary MERS cases apart from hospital settings indicates that the transmission potential and infectivity of such cases is low. The occasional sporadic occurrence of MERS-CoV infection in MERS cases who have any reported animal contact or exposure to MERS cases may be explained by low level infectivity of sub-clinical or asymptomatic cases of MERSCoV infection (Lessler et al. 2016).

\subsection{Natural History and Pathogenesis}

The sporadic nature of MERS-CoV infection with new cases or clusters distributed over a wide geographic area and rather heterogeneous social settings, represents a significant issue for designing and for implementing solid prospective studies. Thus, the main questions about the epidemiology, source of infection, natural history of the disease, the transmission patterns and pathogenesis remain largely unanswered, as yet (Hui and Zumla 2014). Furthermore, the appearance of MERS-CoV, in human populations soon after the SARS-CoV pandemic emphasizes the importance of a One Health approach (Rabozzi et al. 2012) to surveillance of zoonotic infections through integration of human, animal, and environmental health programs. Strengthening surveillance and laboratory networks, as well as training of an effective surveillance workforce is required and needs commitment by all stakeholders, particularly Health Authorities in Middle Eastern Countries.

\section{Clinical Presentation}

There have been several reviews on the clinical aspects of MERS-CoV (Zumla et al. 2015a; Hui and Zumla 2015; The WHO MERS-CoV Research Group 2013; Assiri et al. 2013b; Al-Tawfiq et al. 2014b; ISARIC and Public Health 2014). MERS presents as a clinical spectrum from the asymptomatic, mild, moderate to severe fulminant multisystem disease. There is limited data on pathogenesis due to lack of autopsy or histological studies. MERS-CoV is known to bind to dipeptidyl peptidase 4 (DPP4) receptors (Lu et al. 2013) that are widespread in the body but are primarily located in the lower respiratory tract and thus a typical case of MERS presents with fever, cough, and/or shortness of breath and pneumonia (detailed in Table 1). Severe illness can occur in both immunocompetent and immunocompromised host. In general

Table 1 Clinical and laboratory features of patient with MERS

\begin{tabular}{|c|c|}
\hline $\begin{array}{l}\text { Clinical/laboratory } \\
\text { feature }(\mathrm{s})\end{array}$ & \\
\hline \multirow[t]{2}{*}{ Date of first case (place) } & April 2012 (Zarqa, Jordan) \\
\hline & June 2012 (Jeddah, KSA) \\
\hline \multirow[t]{2}{*}{ Incubation period } & $\begin{array}{l}\text { Mean: } 5.2 \text { days }(95 \% \\
\text { CI:1.9-14.7) }\end{array}$ \\
\hline & Range: $2-14$ days \\
\hline Serial interval & 7.6 days \\
\hline $\begin{array}{l}\text { Basic reproduction } \\
\text { number }\end{array}$ & $<1$ \\
\hline \multicolumn{2}{|l|}{ Age group } \\
\hline Adults & Adults (98\%) \\
\hline Children & Children $(2 \%)$ \\
\hline Age (years): & Range:1-94; \\
\hline Range, Median & Median: 50 \\
\hline Gender (M,F) & M: $64.5 \%, F: 35.5 \%$ \\
\hline \multicolumn{2}{|l|}{ Mortality } \\
\hline $\begin{array}{l}\text { Case fatality rate (CFR)- } \\
\text { overall }\end{array}$ & $40 \% *$ \\
\hline $\begin{array}{l}\text { CFR in patients with } \\
\text { co-morbidities }\end{array}$ & $60 \%$ \\
\hline \multicolumn{2}{|l|}{ Disease progression } \\
\hline $\begin{array}{l}\text { Time from onset to } \\
\text { ventilatory support }\end{array}$ & Median 7 days \\
\hline Time from onset to death & Median 11.5 days \\
\hline \multicolumn{2}{|l|}{ Presenting symptoms } \\
\hline Fever $>38 \mathrm{C}$ & $98 \%$ \\
\hline Chills/rigors & $87 \%$ \\
\hline \multirow[t]{2}{*}{ Cough } & $83 \%$ \\
\hline & $56 \%$ \\
\hline Dry & \multirow[t]{2}{*}{$44 \%$} \\
\hline Productive & \\
\hline Haemoptysis & $17 \%$ \\
\hline Headache & $11 \%$ \\
\hline Myalgia & $32 \%$ \\
\hline Malaise & $38 \%$ \\
\hline Shortness of breath & $72 \%$ \\
\hline
\end{tabular}


Table 1 (continued)

\begin{tabular}{|c|c|}
\hline $\begin{array}{l}\text { Clinical/laboratory } \\
\text { feature(s) }\end{array}$ & \\
\hline Nausea & $21 \%$ \\
\hline Vomiting & $21 \%$ \\
\hline Diarrhoea & $26 \%$ \\
\hline Sore throat & $14 \%$ \\
\hline Rhinorrhoea & $6 \%$ \\
\hline $\begin{array}{l}\text { Co-morbidities } \\
\text { (eg obesity, diabetes, } \\
\text { cardiac disease and lung } \\
\text { disease) }\end{array}$ & $76 \%$ \\
\hline \multicolumn{2}{|l|}{ Laboratory results } \\
\hline CXR abnormalities & $90-100 \%$ \\
\hline $\begin{array}{l}\text { Leukopenia } \\
\left(<4.0 \times 10^{9} / \mathrm{L}\right)\end{array}$ & $14 \%$ \\
\hline $\begin{array}{l}\text { Lymphopenia } \\
\left(<1.5 \times 10^{9} / \mathrm{L}\right)\end{array}$ & $32 \%$ \\
\hline $\begin{array}{l}\text { Thrombocytopenia } \\
\left(<140 \times 10^{9} / \mathrm{L}\right)\end{array}$ & $36 \%$ \\
\hline Elevated LDH & $48 \%$ \\
\hline Elevated ALT & $11 \%$ \\
\hline Elevated AST & $14 \%$ \\
\hline $\begin{array}{l}\text { Risk factors associated } \\
\text { with poor outcome } \\
\text { (severe disease or death) }\end{array}$ & $\begin{array}{l}\text { Any } \\
\text { immunocompromised } \\
\text { state, comorbid illness, } \\
\text { concomitant infections, } \\
\text { low albumin, } \\
\text { age } \geq 65 \text { years }\end{array}$ \\
\hline
\end{tabular}

Compiled from references Zumla et al. (2015), Assiri et al. (2013a, b), Al-Abdallat et al. (2014), Memish et al. (2013a, b), Oboho et al. (2015), The WHO MERSCoV Research Group (2013), Cotten et al. (2013), Azhar et al. (2014)

progression to respiratory and/or renal failure requires intensive care support. Some patients have multi-organ failure and secondary infections leading to septic shock. Mortality rates are high in older people, immunosuppressed patients and in those with co-morbities such as diabetes, cancer, chronic obstructive pulmonary and heart disease.

\section{$4 \quad$ Laboratory Diagnosis and Diagnostics}

Many cases of MERS-CoV can be easily missed since the presentation is that of any community acquired pneumonia (Zumla et al. 2015a; WHO 2015c; Lessler et al. 2016; Al-Tawfiq et al. 2014b; ISARIC and Public Health 2014). Rapid and accurate diagnosis of MERS-CoV infection is important for the clinical management and epidemiological control of MERS-CoV infections. Thus a high degree of clinical awareness of the possibility of MERS-CoV infection is required in all healthcare settings in the Middle East so that an accurate diagnosis can be made and adequate infections control measures promptly implemented (WHO 2015a; ISARIC and Public Health 2014; Zumla and Hui 2014). A history of travel to the Middle East is important for patients presenting in non-Middle Eastern countries (WHO 2015c; ISARIC and Public Health 2014; Zumla and Hui 2014).

Laboratory confirmation of MERS-CoV infection can be obtained by: (a) MERS-CoV specific nucleic acid amplification test (NAAT) with up to two separate targets and/or sequencing; or (b) virus isolation in tissue culture; or (c) serology on serum tested in a WHO collaborating center with established testing methods. Real-time reverse-transcriptase polymerase chain reaction (rRT-PCR) is used (Zumla et al. 2015a; ISARIC and Public Health 2014; Corman et al. 2012, 2014) for specimens collected from the respiratory tract of suspected cases. CDC recommends the collection of three specimen types, lower respiratory, upper respiratory and serum specimens, for testing using the MERS rRT-PCR assay Accurate laboratory molecular diagnostic tests are available (MERS CDC Laboratory testing for MERS-CoV 2016) using highly sensitive and specific Real-time reverse transcription (RT-PCR) assays targeting unique gene regions such as the upE region (gene region upstream to $\mathrm{E}$ gene). These assays have been used for viral load quantitation in studies on viral shedding patterns, optimization of treatment and infection control strategies. Serological tests have been developed for surveillance purposes although they require evaluation in field studies (Park et al. 2015). 


\section{$5 \quad$ Management of Mers Patients}

The clinical management of patients with MERS is largely symptomatic and aimed to reduce the risk of most severe complications, such as secondary infections, and to support renal and respiratory function (Reviewed in Zumla et al. 2015a; WHO 2015b, c; Lessler et al. 2016; Rabozzi et al. 2012; Al-Tawfiq et al. 2014; ISARIC and Public Health England 2014; CDC 2016). Seriously ill patients should receive intensive care. Moreover, the implementation of appropriate infection control measures as soon is possible, is critical for preventing spread of the infection especially in hospitals. Whilst a range of treatments (CDC 2016; WHO 2015b; de Wilde et al. 2013; Falzarano et al. 2013a, b; Chan et al. 2013; Omrani et al. 2014; Shalhoub et al. 2015; Zumla et al. 2016) may be useful (Table 2), currently there are no specific treatments for MERS-CoV infections and no controlled randomized clinical trials of any therapeutic have been conducted to date. A whole range of treatments have been used empirically for serious cases of MERS but there is no solid evidence that any of them can improve the clinical outcome. A range of anti-MERS-CoV drugs and host-directed therapies are in the pipeline (Zumla et al. 2014, 2016; [61]), properly designed, randomized, controlled clinical trials are required to be performed.

\section{Infection Control and Transmission Risk}

There have been several nosocomial outbreaks of MERS-CoV infection within Saudi Arabia (Assiri et al. 2013a; Oboho et al. 2015; Memish et al. 2013b). The largest nosocomial outbreak outside Saudi Arabia occurred in mid-2015 in the Republic of Korea (Petersen et al. 2015; Hui et al. 2015b; Zumla et al. 2015c; Kim et al. 2016b) where the index case was 68-year-old male from Korea who visited several Middle Eastern countries
Table 2 Potentially useful antiviral agents for Middle East respiratory syndrome Coronavirus (MERS-CoV) infection

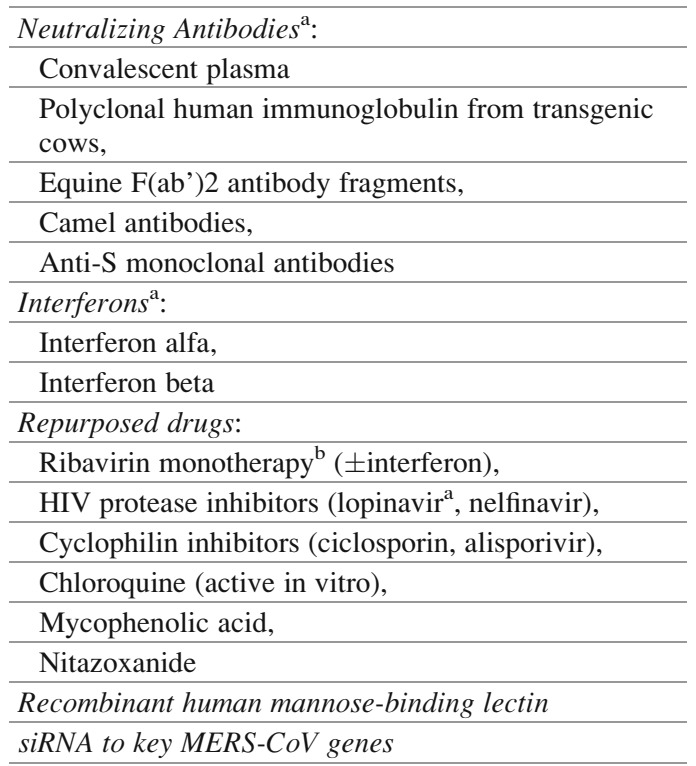

Compiled from references Zumla et al. (2015a), Hui and Zumla (2015)

${ }^{\text {a }}$ Treatment benefits likely to exceed risks

${ }^{\mathrm{b}}$ Risks likely to exceed benefits

(Saudi Arabia, UAE, Bahrain and Qatar) and developed symptoms upon return to Korea and due to lack of isolation and patient consulting several hospitals, a major outbreak ensued involving several hospitals.

Early recognition of MERS cases and rapid implementation of infection control guidance is necessary to prevent nosocomial outbreaks of MERS-CoV. Implementation of effective infection control measures at the first consideration of the diagnosis of MERS-CoV is crucial for prevention of MERS-CoV outbreaks. The first major nosocomial outbreak of MER-CoV in 2013 occurred at Al-Hasa, Saudi Arabia in four hospitals where 21 cases of hospital acquired MERS-CoV infection were confirmed by sequence analyses (Assiri et al. 2013a).

Global public health authorities guidelines (CDC 2016; WHO 2015b) recommend to use, whenever it is possible airborne infection control 
measures for all patients with suspected or confirmed MERS-CoV infection. Moreover airborne infection control measures are mandatory for healthcare workers dealing with patients who undergo aerosol-generating procedures. Several outbreaks of MERS-CoV in Saudi Hospitals in Jeddah, Al-Hasa, and Riyadh were attributed to overcrowding in the emergency departments, uncontrolled patient movement, and high traffic of visitors, lack of infection control stewardship. Effective triage is required at the first suspicion of MERS-CoV and in ill patients with a history of travel to the Middle East. Tracing, screening for symptoms and MERS$\mathrm{CoV}$, and follow up of all contacts, (family, workmates, patients and visitors) is important in preventing further spread. The implementation of extensive contact tracing in order to rapidly diagnose suspected MERS cases and isolate infectious individuals to break the chain of infections is important.

\section{Surveillance, Prevention and Control}

There is currently no licensed vaccine available, although several experimental candidate MERS-CoV vaccines are being developed. For example, researchers at the National Institute of Health in collaboration with other investigators, including the Public Health Agency of Canada, developed an experimental synthetic DNA based vaccine that can generate protective MERS-CoV antibodies in mice, monkeys, and camels (Muthumani et al. 2015). Whilst we await the development of effective MERS-CoV vaccines, public health systems in Western and Middle Eastern countries have put in place surveillance systems for the prompt detection and investigation of new cases and contact tracing. The MERS outbreak in South Korea highlights the potential of MERS-CoV to spread across the globe and cause local outbreaks (Petersen et al. 2015; Hui et al. 2015b). Whilst cases of MERS related to travel to the Middle East have been reported from a wide geographical area, of note is the absence of any significant number of MERS cases (primary or travel related) reported from sub-Saharan African (SSA) countries (WHO 2015c; Zumla et al. 2015c). The reasons why MERS-CoV predominantly affects humans in the Middle East and is not endemic in Africa or Asia where MERS-CoV infected camels and bats are present requires further study (Zumla et al. 2015d). However this observation may reflect the lack of clinical awareness of MERS and that diagnosis and treatment of respiratory tract infections largely remains empiric, without laboratory confirmation.

An estimated 10 million visitors from over 184 countries travel to Saudi Arabia to participate in Hajj pilgrimage, the mini-pilgrimage Umrah or during the month of Ramadan, the vast majority come from developing countries (Memish et al. 2014a). If MERS-CoV was a major public health risk, 4 years after its first discover one would have expected cases of MERS-CoV infection in pilgrims. There were no cases of MERS reported during the 2012, 2013, 2014 and 2015 among Hajj pilgrimages (Waldron and Doherty 2015; Lessler et al. 2014). It is possible that like SARS-CoV, MERS-CoV will die out with time. Conversely it is also possible that MERS-CoV will mutate and increase its transmission potential and the risk of MERS-CoV spreading globally remains. Coker and colleagues (Soliman et al. 2015) estimated the potential risk of MERS-CoV infection to pilgrims who visit Saudi Arabia from different regions of the world based on the most likely scenario using recent pilgrim numbers for sub-Saharan Africa. They predict that there will be at most ten returning pilgrims each year with MERS-CoV infections. As the recent Ebola Virus Disease epidemic in West Africa illustrates, African and Asian countries are vulnerable to a Korea-like MERS-CoV outbreak (Zumla et al. 2015e).

A recent study published in Science by Sabir and colleagues (Sabir et al. 2016) found that at least five lineages of MERS-CoV are circulating in Saudi Arabian camels. These results suggest that multiple lineages of MERS-CoV have been co-circulating in Saudi Arabia confirming what 
was suspected before (Cotten et al. 2013b, 2014). This is a pre-requisite for recombination to occur and it is no surprise that Sabir et al. identified at least six recombination events, showing that recombination is frequent in MERS-CoV. Of interest was that one lineage sequenced by Sabir et al (Sabir et al. 2016) was associated with the 2015 Riyadh nosocomial outbreak (Balkhy et al. 2016), and the MERS-CoV sequenced from the Republic of Korean outbreak also had a recombinant origin. It's been suggested that the recombinant lineage originated between December 2013 and June 2014, and has rapidly become the predominant lineage in Saudi Arabian camels since November 2014.

MERS-CoV remains a major threat for global health. With recent outbreaks of Ebola virus and Zika virus a coordinated global response is needed to tackle emerging and re-emerging infectious diseases with epidemic potential (Zumla et al. 2015e; Petersen et al. 2016; Memish et al. 2014b). Meanwhile there are critical knowledge gaps related to MERS-CoV which, require to be filled (The WHO MERSCoV Research Group 2013; Hui and Zumla 2014).

\section{References}

Al-Abdallat MM, Payne DC, Alqasrawi S (2014) Jordan MERS-CoV investigation team. Hospital-associated outbreak of Middle East respiratory syndrome coronavirus: a serologic, epidemiologic, and clinical description. Clin Infect Dis 59:1225-1233

Al-Tawfiq JA, Zumla A, Gautret P, Gray GC, Hui DS, Al-Rabeeah AA, Memish ZA (2014a) Surveillance for emerging respiratory viruses. Lancet Infect Dis 14 (10):992-1000

Al-Tawfiq JA, Zumla A, Memish ZA (2014b) Coronaviruses: severe acute respiratory syndrome coronavirus and Middle East respiratory syndrome coronavirus in travelers. Curr Opin Infect Dis 27(5):411-417

Annan A, Baldwin HJ, Corman VM et al (2013) Human betacoronavirus 2c EMC/2012-related viruses in bats. Ghana and Europe Emerg Infect Dis 19:456-459

Assiri A, McGeer A, Perl TM (2013a) et al; KSA MERS$\mathrm{CoV}$ investigation team. Hospital outbreak of Middle East respiratory syndrome coronavirus. N Engl J Med 369:407-416
Assiri A, Al-Tawfiq JA, Al-Rabeeah AA, Al-Rabiah FA, Al-Hajjar S, Al-Barrak A, Flemban H, Al-Nassir WN, Balkhy HH, Al-Hakeem RF, Makhdoom HQ, Zumla A, Memish ZA (2013b) Epidemiological, demographic, and clinical characteristics of 47 cases of Middle East respiratory syndrome coronavirus disease from Saudi Arabia: a descriptive study. Lancet Infect Dis 13(9):752-761

Azhar EI, El-Kafrawy SA, Farraj SA, Hassan AM, Al-Saeed MS, Hashem AM et al (2014) Evidence for camel-to-human transmission of MERS coronavirus. N Engl J Med 370(26):2499-2505

Balkhy HH, Alenazi TH, Alshamrani MM, BaffoeBonnie H, Al-Abdely HM, El-Saed A, Al Arbash HA, Al Mayahi ZK, Assiri AM, Bin Saeed A (2016) Notes from the field: nosocomial outbreak of Middle East respiratory syndrome in a large tertiary care hospital - Riyadh, Saudi Arabia, 2015. MMWR Morb Mortal Wkly Rep 65(6):163-164. doi:10.15585/ mmwr.mm6506a5

CDC (2016) Middle East Respiratory Syndrome (MERS). http://www.cdc.gov/coronavirus/mers/. Accessed 28 Feb 2016

Chan JF, Chan KH, Kao RY et al (2013) Broad-spectrum antivirals for the emerging Middle East respiratory syndrome coronavirus. J Infect 67:606-616

Corman VM, Muller MA, Costabel U, Timm J, Binger T, Meyer B et al (2012) Assays for laboratory confirmation of novel human coronavirus (hCoV-EMC) infections. Euro Surveill 17:20334. [PubMed]

Corman VM, Ithete NL, Richards LR, Schoeman MC, Preiser W, Drosten C et al (2014) Rooting the phylogenetic tree of Middle East respiratory syndrome coronavirus by characterization of a conspecific virus from an African bat. J Virol 88:11297-11303. doi:10.1128/JVI.01498-14 [PMC free article] [PubMed] [Cross Ref]

Cotten M, Watson SJ, Kellam P, Al-Rabeeah AA, Makhdoom HQ, Assiri A, Al-Tawfiq JA, Alhakeem RF, Madani H, AlRabiah FA, Al Hajjar S, Al-nassir WN, Albarrak A, Flemban H, Balkhy HH, Alsubaie S, Palser AL, Gall A, Bashford-Rogers R, Rambaut A, Zumla AI, Memish ZA (2013a) Transmission and evolution of the Middle East respiratory syndrome coronavirus in Saudi Arabia: a descriptive genomic study. Lancet 382(9909):1993-2002

Cotten M, Watson SJ, Kellam P, Al-Rabeeah AA, Makhdoom HQ, Assiri A et al (2013b) Transmission and evolution of the Middle East respiratory syndrome coronavirus in Saudi Arabia: a descriptive genomic study. Lancet 382:1993-2002

Cotten M, Watson SJ, Zumla AI, Makhdoom HQ, Palser AL, Ong SH, Al Rabeeah AA, Alhakeem RF, Assiri A, Al-Tawfiq JA, Albarrak A, Barry M, Shibl A, Alrabiah FA, Hajjar S, Balkhy HH, Flemban H, Rambaut A, Kellam P, Memish ZA (2014) Spread, circulation, and evolution of the Middle East respiratory syndrome coronavirus. mBio 5((1):e01062 
de Groot RJ, Baker SC, Baric RS, Brown CS, Drosten C, Enjuanes L, Fouchier RA, Galiano M, Gorbalenya AE, Memish ZA, Perlman S, Poon LL, Snijder EJ, Stephens GM, Woo PC, Zaki AM, Zambon M, Ziebuhr J (2013) Middle East respiratory syndrome coronavirus (MERS-CoV): announcement of the coronavirus study group. J Virol 87(14):7790-7792

de Wilde AH, Raj VS, Oudshoorn D et al (2013) MERScoronavirus replication induces severe in vitro cytopathology and is strongly inhibited by cyclosporin A or interferon- $\alpha$ treatment. J Gen Virol 94:1749-1760

Du L, Han GZ (2016) Deciphering MERS-CoV evolution in dromedary camels. Trends Microbiol 24(2):87-89. doi:10.1016/j.tim.2015.12.013. Epub 2016 Jan 8

Falzarano D, de Wit E, Martellaro C et al (2013a) Inhibition of novel $\beta$ coronavirus replication by a combination of interferon- $\alpha 2 b$ and ribavirin. Sci Rep 3:1686

Falzarano D, de Wit E, Rasmussen AL et al (2013b) Treatment with interferon- $\alpha 2 b$ and ribavirin improves outcome in MERS-CoV-infected rhesus macaques. Nat Med 19:1313-1317

Gossner C, Danielson N, Gervelmeyer A, Berthe F, Faye B, Kaasik Aaslav K, Adlhoch C, Zeller H, Penttinen P, Coulombier D (2016) Human-dromedary camel interactions and the risk of acquiring zoonotic Middle East respiratory syndrome coronavirus infection. Zoonoses Public Health 63(1):1-9

Haagmans BL, Al Dhahiry SH, Reusken CB et al (2014) Middle East respiratory syndrome coronavirus in dromedary camels: an outbreak investigation. Lancet Infect Dis 14:140-145

Hemida MG, Perera RA, Al Jassim RA et al (2014) Seroepidemiology of Middle East respiratory syndrome (MERS) coronavirus in Saudi Arabia (1993) and Australia (2014) and characterisation of assay specificity. Euro Surveill 19:20828

Hijawi B, Abdallat M, Sayaydeh A et al (2013) Novel coronavirus infections in Jordan, April 2012: epidemiological findings from a retrospective investigation. East Mediterr Health J 19(Suppl 1):S12-S18

Hui DS, Zumla A (2014) Advancing priority research on the Middle East respiratory syndrome coronavirus. J Infect Dis 209:173-176

Hui DS, Zumla A (2015) Emerging respiratory tract viral infections. Curr Opin Pulm Med 21(3):284-292

Hui DS, Perlman S, Zumla A (2015a) Spread of MERS to South Korea and China. Lancet Respir Med. pii: S2213-2600(15)00238-6. doi: 10.1016/S22132600(15)00238-6. [Epub ahead of print]

Hui DS, Perlman S, Zumla A (2015a) Spread of MERS to South Korea and China. Lancet Respir Med 3(7):509-510

ISARIC and Public Health England (2014) Treatment of MERS-CoV: information for clinicians. Clinical decision-making support for treatment of MERSCoV patients v2.0 14 July 2014. Available at https:// www.gov.uk/government/uploads/system/uploads/ attachment_data/file/360424/MERS_COV_information_ for_clinicians_17_July.pdf
Kim YJ, Cho YJ, Kim DW, Kim H, Park S et al (2015) Complete genome sequence of Middle East respiratory syndrome coronavirus KOR/KNIH/ 002_05_2015, isolated in South Korea. Genome Announc 3:e00787-15. [PMC free article] [PubMed]

Kim Y, Cheon S, Min CK, Sohn KM, Kang YJ, Cha YJ, Kang JI, Han SK, Ha NY, Kim G, Aigerim A, Shin HM, Choi MS, Kim S, Cho HS, Kim YS, Cho NH. Spread of Mutant Middle East Respiratory Syndrome Coronavirus with Reduced Affinity to Human CD26 during the South Korean Outbreak. MBio. 2016 Mar 1;7(2):e00019. doi: 10.1128/mBio.00019-16. PMID: 26933050.

Kim JI, Kim YJ, Lemey P, Lee I, Park S, Bae JY, Kim D, Kim H, Jang SI, Yang JS, Kim H, Kim DW, Nam JG, Kim SS, Kim K, Myun Lee J, Song MK, Song D, Chang J, Hong KJ, Bae YS, Song JW, Lee JS, Park MS (2016b) The recent ancestry of Middle East respiratory syndrome coronavirus in Korea has been shaped by recombination. Sci Rep 6:18825

Lessler J, Rodriguez-Barraquer I, Cummings DA, Garske T, Van Kerkhove M, Mills H, Truelove S, Hakeem R, Albarrak A, Ferguson NM (2014) MERS-CoV Scenario Modeling Working Group. Estimating potential incidence of MERS-CoV associated with Hajj Pilgrims to Saudi Arabia. PLoS Curr 6. pii: ecurrents. outbreaks. c5c9c9abd636164a9b6fd4dbda974369

Lessler J, Salje H, Van Kerkhove MD, Ferguson NM, Cauchemez S, Rodriquez-Barraquer I, Hakeem R, Jombart T, Aguas R, Al-Barrak A, Cummings DA (2016) MERS-CoV Scenario and Modeling Working Group. Estimating the severity and subclinical burden of Middle East respiratory syndrome coronavirus infection in the Kingdom of Saudi Arabia. Am J Epidemiol. pii: kwv452. [Epub ahead of print]

Lu G, Hu Y, Wang Q, Qi J, Gao F, Li Y, Zhang Y, Zhang W, Yuan Y, Bao J, Zhang B, Shi Y, Yan J, Gao GF (2013) Molecular basis of binding between novel human coronavirus MERS-CoV and its receptor CD26. Nature 500(7461):227-231

McCloskey B, Dar O, Zumla A, Heymann DL (2014) Emerging infectious diseases and pandemic potential: status quo and reducing risk of global spread. Lancet Infect Dis 14(10):1001-1010

Memish ZA, Zumla AI, Al-Hakeem RF et al (2013a) Family cluster of Middle East respiratory syndrome coronavirus infections. N Engl J Med 368:2487-2494

Memish ZA, Zumla A, Assiri A (2013b) Middle East respiratory syndrome coronavirus infections in health care workers. N Engl J Med 369(9):884-886

Memish ZA, Mishra N, Olival KJ et al (2013c) Middle East respiratory syndrome coronavirus in bats, Saudi Arabia. Emerg Infect Dis 19:1819-1823

Memish ZA, Zumla A, Alhakeem RF, Assiri A, Turkestani A, Al Harby KD, Alyemni M, Dhafar K, Gautret P, Barbeschi M, McCloskey B, Heymann D, Al Rabeeah AA, Al-Tawfiq JA (2014a) Hajj: 
infectious disease surveillance and control. Lancet 383(9934):2073-2082

Memish ZA, Zumla A, McCloskey B, Heymann D, Al Rabeeah AA, Barbeschi M, Horton R (2014b) Mass gatherings medicine: international cooperation and progress. Lancet 383(9934):2030-2032

MERS CDC Laboratory testing for MERS-CoV (2016) http://www.cdc.gov/coronavirus/MERS/lab/lab-testing. html. Accessed 24 Feb 2016

Meyer B, Muller MA, Corman VM et al (2014) Antibodies against MERS coronavirus in dromedary camels, United Arab Emirates, 2003 and 2013. Emerg Infect Dis 20:552-559

Muller MA, Corman VM, Jores J et al (2014) MERS coronavirus neutralizing antibodies in camels, Eastern Africa, 1983-1997. Emerg Infect Dis 20:2093-2095

Muthumani K, Falzarano D, Reuschel EL, Tingey C, Flingai S, Villarreal DO, Wise M, Patel A, Izmirly A, Aljuaid A, Seliga AM, Soule G, Morrow M, Kraynyak KA, Khan AS, Scott DP, Feldmann F, LaCasse R, Meade-White K, Okumura A, Ugen KE, Sardesai NY, Kim JJ, Kobinger G, Feldmann H, Weiner DB (2015) A synthetic consensus anti-spike protein DNA vaccine induces protective immunity against Middle East respiratory syndrome coronavirus in nonhuman primates. Sci Transl Med 7(301):301ra132

Oboho IK, Tomczyk SM, Al-Asmari AM et al (2015) 2014 MERS-CoV outbreak in Jeddah-A link to health care facilities. N Engl J Med 372:846-854

Omrani AS, Saad MM, Baig K et al (2014) Ribavirin and interferon alfa-2a for severe Middle East respiratory syndrome coronavirus infection: a retrospective cohort study. Lancet Infect Dis 14:1090-1095

Park SW, Perera RA, Choe PG, Lau EH, Choi SJ, Chun JY, Oh HS, Song KH, Bang JH, Kim ES, Kim HB, Park WB, Kim NJ, Poon LL, Peiris M, Oh MD (2015) Comparison of serological assays in human Middle East respiratory syndrome (MERS)-coronavirus infection. Euro Surveill 15:20(41). doi:10.2807/1560-7917

Peiris JS, Yuen KY, Osterhaus AD, Stohr K (2003) The severe acute respiratory syndrome. N Engl J Med 349:2431-2441

Penttinen PM, Kaasik-Aaslav K, Friaux A et al (2013) Taking stock of the first 133 MERS coronavirus cases globally - Is the epidemic changing? Euro Surveill 18(39):20596

Petersen E, Hui DS, Perlman S, Zumla A (2015) Middle East respiratory syndrome- advancing the public health and research agenda on MERS- lessons from the South Korea outbreak. Int J Infect Dis 36:54-55

Petersen E, Wilson ME, Touch S, McCloskey B, Mwaba P, Bates M, Dar O, Mattes F, Kidd M, Ippolito G, Azhar EI, Zumla A (2016) Rapid spread of Zika virus in the Americas - implications for public health preparedness for mass gatherings at the 2016 Brazil Olympic Games. Int J Infect Dis 44:11-15

Rabozzi G, Bonizzi L, Crespi E, Somaruga C, Sokooti M, Tabibi R, Vellere F, Brambilla G, Colosio C (2012)
Emerging zoonoses: the "one health approach". Saf Health Work 3(1):77-83

Reusken CB, Haagmans BL, Müller MA et al (2013) Middle East respiratory syndrome coronavirus neutralising serum antibodies in dromedary camels: a comparative serological study. Lancet Infect Dis 13:859-866

Reusken CB, Messadi L, Feyisa A et al (2014) Geographic distribution of MERS coronavirus among dromedary camels, Africa. Emerg Infect Dis 20:1370-1374

Sabir JS, Lam TT, Ahmed MM, Li L, Shen Y, Abo-Aba SE, Qureshi MI, Abu-Zeid M, Zhang Y, Khiyami MA, Alharbi NS, Hajrah NH, Sabir MJ, Mutwakil MH, Kabli SA, Alsulaimany FA, Obaid AY, Zhou B, Smith DK, Holmes EC, Zhu H, Guan Y (2016) Co-circulation of three camel coronavirus species and recombination of MERS-CoVs in Saudi Arabia. Science 351(6268):81-84

Shalhoub S, Farahat F, Al-Jiffri A et al (2015) IFN- $\alpha 2$ a or IFN- $\beta 1 \mathrm{a}$ in combination with ribavirin to treat Middle East respiratory syndrome coronavirus pneumonia: a retrospective study. $\mathrm{J}$ Antimicrob Chemother 70:2129-2132

Soliman T, Cook AR, Coker RJ (2015) Pilgrims and MERS-CoV: what's the risk? Emerg Themes Epidemiol 12:3

The WHO MERS-CoV Research Group (2013) State of knowledge and data gaps of Middle East respiratory syndrome coronavirus (MERS-CoV) in humans. PLoS Curr 5. pii: ecurrents. outbreaks.0bf719e352e7478f8ad85fa30127ddb8

Waldron G, Doherty L (2015) Low public health risk of MERS-CoV in people returning from the Hajj. BMJ 351:h5543

Wang Y, Liu D, Shi W, Lu R, Wang W, Zhao Y et al (2015) Origin and possible genetic recombination of the Middle East respiratory syndrome coronavirus from the first imported case in China: phylogenetics and coalescence analysis. MBio 6:e01280-15. doi:10. 1128/mBio.01280-15 [PMC free article] [PubMed] [Cross Ref

WHO (2015a) Clinical management of severe acute respiratory infection when Middle East respiratory syndrome coronavirus (MERS-CoV) infection is suspected. Interim guidance. Updated 2 July 2015. Accessed 28 Feb 2016. Available at http://www.who. int/csr/disease/coronavirus_infections/case-managementipc/en/

WHO (2015b) Clinical management of severe acute respiratory infection when Middle East respiratory syndrome coronavirus (MERS-CoV) infection is suspected. Interim guidance. Updated 2 July 2015WHO/MERS/Clinical/15.1. http://apps.who.int/ iris/bitstream/10665/178529/1/WHO_MERS_Clinical_ 15.1_eng.pdf?ua $=1$

WHO (2015c) Outbreaks and emergencies Middle East respiratory syndrome coronavirus (MERS-CoV) MERS-CoV in Republic of Korea at a glance Accessed 28 Nov 2016 Available at 
http://www.wpro.who.int/outbreaks_emergencies/wpro_ coronavirus/en/

WHO (2016) Middle East respiratory syndrome coronavirus (MERS-CoV) - update. Disease outbreak news. Accessed 28 November 2016. Available at: http:// www.who.int/emergencies/mers-cov/en/

Younan M, Bornstein S, Gluecks IV. MERS and the dromedary camel trade between Africa and the Middle East. Trop Anim Health Prod. 2016 Aug;48(6):127782. doi:10.1007/s11250-016-1089-3. PubMed PMID: 27324244.

Yu IT, Qiu H, Tse LA, Wong TW (2014) Severe acute respiratory syndrome beyond Amoy Gardens: completing the incomplete legacy. Clin Infect Dis 58:683-686

Zaki AM, van Boheemen S, Bestebroer TM et al (2012) Isolation of a novel coronavirus from a man with pneumonia in Saudi Arabia. N Engl J Med 367:1814-1820

Zumla A, Hui DS (2014) Infection control and MERS-CoV in health-care workers. Lancet 383(9932): 1869-1871

Zumla A, Memish ZA, Maeurer M, Bates M, Mwaba P, Al-Tawfiq JA, Denning DW, Hayden FG, Hui DS (2014) Emerging novel and antimicrobial-resistant respiratory tract infections: new drug development and therapeutic options. Lancet Infect Dis 14(11):1136-1149
Zumla A, Hui DS, Perlman S (2015a) State of the ART Seminar: Middle East respiratory syndrome. The Lancet. pii: S0140-6736(15)60454-8. [Epub ahead of print]

Zumla A, Azhar EI, Arabi Y, Alotaibi B, Rao M, McCloskey B, Petersen E, Maeurer M (2015b) Hostdirected therapies for improving poor treatment outcomes associated with the Middle East respiratory syndrome coronavirus infections. Int J Infect Dis. pii: S1201-9712(15)00215-5

Zumla A, Perlman S, McNabb SJ, Shaikh A, Heymann DL, McCloskey B, Hui DS (2015c) Middle East respiratory syndrome in the shadow of Ebola. Lancet Resp Med 3(2):100-102

Zumla A, Rustomjee R, Ntoumi F, Mwaba P, Bates M, Maeurer M, Hui DS, Petersen E (2015d) Middle East respiratory syndrome--need for increased vigilance and watchful surveillance for MERS-CoV in sub-Saharan Africa. Int J Infect Dis 37:77-79

Zumla A, Heymann D, Ippolito G (2015e) Be prepared: Europe needs Ebola outbreak consortium. Nature 523 (7558):35. doi:10.1038/523035b

Zumla A, Chan J, Azhar EI, Hui D, Yuen KY (2016) Coronaviruses - drug discovery and therapeutic options. Nat Rev Drug Discov. doi:10.1038/nrd. 2015.37. [Epub ahead of print] 